\title{
Effect of Usability of Mathematics Laboratory Facilities on the Achievement of Junior Secondary School Students in Number and Numeration
}

\author{
Nasirudeen Ayinde MALIK ${ }^{1}$ Kennedy Otuniuya AKUDO ${ }^{2}$ Debo Sulaimon ARIKEWUYO ${ }^{3}$ \\ Gafar Adeboye OGUNLEYE ${ }^{4}$ \\ 1.Bakre Disu Oshodi Memorial High School, Oniwaya, Agege, Lagos State, Nigeria \\ 2.Mathematics Department, Adeniran Ogunsanya College of Education Oto-Ijanikin, Lagos State, Nigeria \\ 3.Lagos State Education District III, Falomo, Ikoyi, Lagos State, Nigeria \\ 4.Margdave Lagacy College, Ikorodu, Lagos State, Nigeria
}

\begin{abstract}
The study focused on the effect of the usability of mathematics laboratory facilities on achievement of students in number and numeration at junior secondary schools in Lagos State, Nigeria. Purposive sampling was used to select two schools in Ikorodu Zone, Education District II and 59 students from two intact classes were selected. The quasi-experimental research design was adopted which involved pre-test and post-test non-equivalent control group. The instrument used for the study was the Number and Numeration Achievement Test (NNAT) which consisted 20 objective questions was adopted from Lagos State Unified Basic Education Certificate Examination past questions validated by Lagos State Ministry of Education Examinations Board. The reliability of the instrument was 0.73 with the use of Spearman rank correlation coefficient. The two research questions raised were answered with the aid of means and Bar-charts, while the three null hypotheses were tested using Analysis of CoVariance (ANCOVA). The findings revealed that the use of mathematics laboratory enhanced achievement in Number and Numeration unlike conventional method. It also showed that there is no significant effect of gender on the achievement of students taught number and numeration using mathematics laboratory approach. Lastly, there is no significant interaction effect of Mathematics laboratory method and gender on students' achievement scores. It was recommended that mathematics laboratory should be established, and laboratory approach of teaching mathematics should be adopted in our schools.
\end{abstract}

Keywords: Usability, Laboratory Facilities, Achievement, Number, Numeration

DOI: $10.7176 / \mathrm{JEP} / 12-21-01$

Publication date:July $31^{\text {st }} 2021$

\section{Introduction}

Despite the fact that Mathematics Laboratories serve as fundamental sources of creative thinking, skill development and problem solving for Junior Secondary School students, its facilities are seldom used by Mathematics teachers (Shreedevi \& Asha, 2014). Well-equipped Mathematics Laboratory at the basic school level has given birth to scientific and technological growth in manpower among developed nations (Imoko \& Isa, 2015).Beyond availability of Mathematics laboratory materials, Malik (2017) opined that adequate use of Mathematics laboratory prepares students for a useful and meaningful living, because Mathematics is the language and key to everyday activities of mankind in the world of science and technology. For the fact that Mathematics Laboratory is equipped with numbers, symbols, objects, counting devices, measuring materials, number patterns and relationships of quantities, it is central to mathematics curriculum at the primary and secondary levels in Nigeria (Akanmu, 2017). Nneji and Alio (2017) observed that Mathematics as a subject does not only deal with manipulation of numbers, but goes further to explain practical relationships between the numbers, attributes and application of the numbers to solving day to day practical life problems.

Imoko and Isa (2015) posited that Mathematics laboratory provides the bedrock and foundation for creative thinking and cognitive development and should therefore, be emphasised early in the academic life of the nation's citizenry. Abdulhamid, Abubakar, and Tela (2017) expressed that the use of Mathematics laboratory requires application of effective tools that lead to active learning, but the absence of this will make the students not to participate actively in Mathematics class. National Open University of Nigeria (NOUN) (2012) emphasized that teaching objectives in mathematics at junior secondary school level has been filled with memorization of facts while calculating and manipulating numbers. The use of Mathematics Laboratory makes teaching and learning of basic concept like number and numeration orderly.

Number and numeration is a basic concept of mathematics from which algebra was developed. The various human daily-life activities on number and numeration create the sense of mathematics. The number is a sense of ability to recognize quantity of single or collection of objects. There are so many developed number systems in the world, among them Hindu-Arabic, Devanagari, Roman figure etc. are the famous and useable number system in the world. The ancient Babylonians used the sexagesimal (base 60) number system, rather than a base 10 
(decimal) in Mathematics Lab to advanced number system even for today's standards. They divided the day into twenty-four hour, each hour into sixty minutes and each minute into sixty seconds. This form of counting still survived till today.

The number systems of most countries in the modern world used today for counting, calculating and reading and writing numbers is called the decimal system because it is based on the number 10 . The concept of number and symbol are taught in preliminary phase of learning. Number and symbols are the fundamental basis of mathematics and mathematics learning. The number is used formally and informally in daily human-life activities. Few peoples follow mathematics professionally but number has the immense link in each individual's life and culture. Number and numeration is the essential part of the mathematics as well as human life (Farlex Encyclopedia, 2020). This aspect of mathematics can be improved when laboratory approach is used in teaching.

Mathematics laboratory was defined by Shreedevi and Asha (2014) as a place rich in manipulative materials, to which learners have access to handle them, perform mathematical experiments, play mathematical games, solve mathematical puzzles and become involved in discovery activities. Laboratory is simply a room or building fitted with equipment for scientific experimentation e.g Physics laboratory, Biology laboratory, Chemistry laboratory, Mathematics laboratory etc while Mathematics laboratory is a method of teaching whereby students work in an informal manner, move round, discuss and choose their materials and method of solving a problem, assignment or task. It is based on learning by doing. The use of mathematics laboratory helps to integrate theory and practical work in mathematics teaching/learning. While Adenegan (2012) was highlighting the functions of mathematics laboratory in every school, the advantages were itemized to include: display of mathematics information, avenue for experimentation, pool of storage for mathematical materials for easy access, and removal of abstractness for effective teaching and learning.

Furthermore, the functions were listed as it: permits students to learn abstract concepts through concrete experiences and thus increase their understanding of those ideas; enables students to personally experience the joy of discovering principle and relationships; arouses interest and motivates learning; cultivates favourable attitudes towards mathematics; enriches and varies instructions; encourages and develops creative problems solving ability; allows for individual differences in manner and speed at which students learn; makes students to see the origin of mathematical ideas and participates in mathematics in the marking; and allows students to actually engage in the doing rather than being a passive observer or recipient of knowledge in the learning process (Adenegan, 2012).

A number of instructional strategies have been successfully used to improve students' achievement in mathematics. Adeniran (2016) stated that laboratory instructional approach gives a new approach to mathematics learning because it provides a non-threatening, realistic and concrete approach to learning of mathematics as opposed to the difficulty encountered in learning the formal abstract treatment of the typical textbook. Kurumeh (2007) said that empirical learning through direct involvement of gender arouses their interest and helps to sustain attention. Pasha, Rao and Veerababu (2012) examined the impact of mathematics laboratory on students' academic achievement in high school. It was established that the use of the mathematics laboratory enhanced students' achievement and bridged the achievement gap between male and female students in mathematics. Laboratory instructional approach provides gender with opportunity to use their senses so that at the end of instruction, they can perform the teachers' stated objectives. These resources whether they are real or representation make the learning content meaningful, preserve and extend knowledge to unlimited number of mathematics learners. Mathematics laboratory is not gender sensitive; therefore both male and female students should be involved in mathematics laboratory instructional approach to enhance their achievement in mathematics. It is evident from the findings of Manjunath (2018) that there is no disparity in the achievement of male and female mathematics students taught mathematics using laboratory instructional approach. Therefore, the laboratory instructional teaching approach is suitable for both male and female in the teaching and learning of mathematics.

Among all the subjects that students encounter in schools, mathematics is the most abstract and the most symbolic (Mckillipet al, 2018). The nature of mathematics and the problem of ineffective teaching can be tackled through planned and intelligent application of the mathematics laboratory. The need for the development and establishment of mathematics laboratories has long been expressed in Nigeria and elsewhere. It is obvious that the attitudes of teachers and students towards the subject is not encouraging, most of the students in junior secondary schools do not like the subject and considered it to be very difficult(Manjunath, 2018).. Based on the advantages enumerated above, it is expected that teaching/learning of mathematics using laboratory approach could help reduce the abstractness of the subject and facilitate students understanding and consequently lead to the improvement in students' mathematics achievement.

\section{Statement of the Problem}

Abiami and Odok (2016) opined that evidence of poor achievement in mathematics by junior secondary school students point to the fact that the most desired technological, scientific and business application of mathematics cannot be sustained. This makes it paramount to seek for an approach for teaching and learning of mathematics that aims at improving its understanding and achievement by students in Basic Education Certificate Examination 
(BECE).Many students in junior secondary schools today show negative attitude towards the learning of mathematics. Nwabueze (2010) observed that most students think that mathematics means getting the solution of a problem right or wrong. When they get it wrong they think that they are not good enough in mathematics and loose interest in learning. The Society's believe about mathematics itself seem to drive away many students from liking the subject. The conventional instruction used all along had been found to be inadequate for effective teaching.

Etsu (2017) and Manjunath (2018) observed that lack of mathematics laboratory and mathematics teachers' non-use of laboratory technique in teaching mathematics is one of the major factors that contribute to poor academic achievement in mathematics by secondary school students. The West African Examinations Council (WAEC), Chief examiners' Reports $(2010,2011,2012 \& 2018)$ affirmed that candidates lack requisite practical skills to answer the questions raised in number and numeration, which point to the fact that the most desired technological, scientific and business application of mathematics cannot be sustained.

This makes it paramount to seek for an approach for teaching number and numeration that aims at improving its understanding and academic achievement by students. Ogunkunle(2000) asserted that lack of mathematics laboratory and mathematics teachers' non-use of laboratory technique in teaching number and numeration is one of the major factors that contribute to poor academic achievement of students in number and numeration at junior secondary school. Therefore, the study was designed to find out the effects of using mathematics laboratory on the academic achievement of students in number and numeration at junior secondary school in Lagos State.

\section{Purpose of the Study}

The main purpose of this study is to investigate the effects of mathematics laboratory on the academic achievement of students in number and numeration at junior secondary school in Lagos State. Specifically, the study examined the:

(1) Effect of mathematics laboratory approach on students achievement in number and numeration at Junior Secondary School level.

(2) Effect of Mathematics laboratory approach on male and female students achievement in number and numeration at Junior Secondary School level.

Interaction effects of mathematics laboratory and gender on students achievement in number and numeration at junior secondary school level.

\section{Research Questions}

The following research questions were addressed in the study:

(1) What are the achievements of students in number and numeration before and after exposure to math lab facilities and conventional method?

(2) Do students differ in achievement by gender when taught number and numeration using mathematics laboratory facilities?

\section{Research Hypotheses}

The following hypotheses were formulated and tested at 5\% level of significance:

$\mathrm{Ho}_{1}$ : There is no significant effect of the usability of Mathematics laboratory facilities on the mean achievement scores of students taught Number and Numeration.

$\mathrm{Ho}_{2}$ : There is no significant effect of gender on the mean achievement scores of students taught Number and Numeration using mathematics laboratory approach.

$\mathrm{Ho}_{3}$ : There is no significant interaction effect of Mathematics laboratory method and gender on students mean achievement scores in Number and Numeration.

\section{Methodology}

The quasi-experimental design involving a pre-test and post-test non-equivalent control group was used for this study. The population of the study was made up of all the Junior Secondary School students in Ikorodu Zone of Education Districts II in Lagos State. Two schools were randomly selected from which two intact classes were taken. One class was used as experimental group and the other as control group. Out of the 59 Junior Secondary School 3 students that participated, there were 28 males and 31 females; 12 males participated in mathematics laboratory activities and 16 were in conventional group. On the other hand, 16 females used mathematics laboratory and 15 were in conventional group. The experimental group was exposed to Mathematics laboratory approach to number and numeration for six weeks, while the control group was taught the same topic conventionally for six weeks. A pretest was administered to the two groups in order to determine equivalence in their ability. Then a post-test was administered for 30 minutes to both groups to evaluate the effectiveness of the treatment after the teaching. The Number and Numeration Achievement Test (NNAT) for both pre-test and posttest which consists of 20 objective test items with options A-D, was adopted from Lagos State Unified Examination 
past questions conducted by Lagos State Ministry of Education Examinations Board. It has a Spearman rank correlation coefficient of $73 \%$. The research questions were answered using means and bar-charts, while hypotheses were tested using analysis of variance (ANCOVA) also known as F-test at 0.05 level of significance.

\section{Results}

RQ1. What are the achievements of students in number and numeration before and after exposure to mathematics laboratory facilities and conventional method?

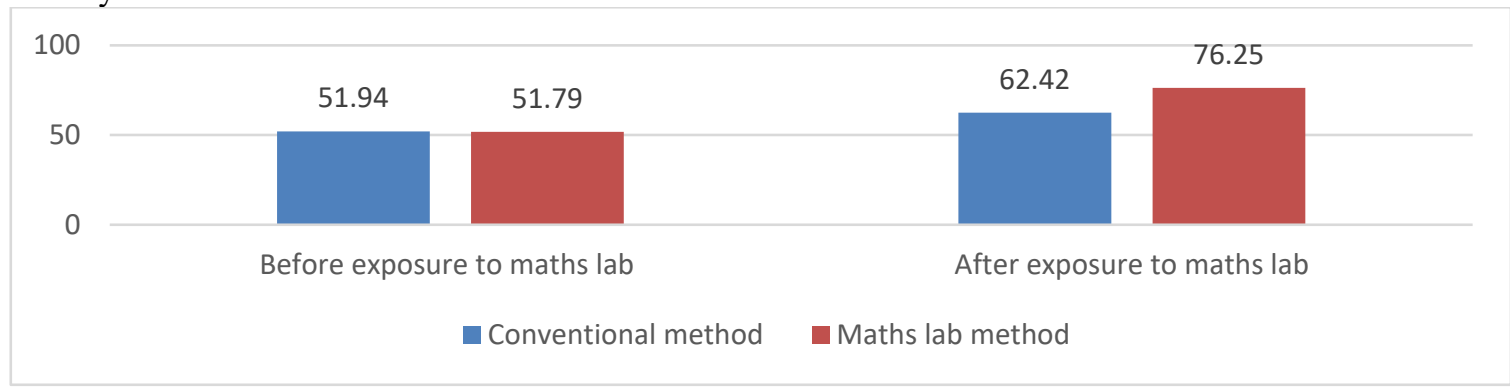

Fig 1. Students' pre and post achievements in number and numeration using mathematics laboratory

The result in Fig 1 showed that students' mean scores before treatment were $51.94 \%$ and $51.79 \%$, for conventional and mathematics laboratory approaches respectively, but after the treatment their mean scores rose to $62.42 \%$ and $76.25 \%$ for conventional and mathematics laboratory groups respectively.

RQ2. Do students differ in achievement by gender when taught number and numeration using mathematics laboratory facilities?

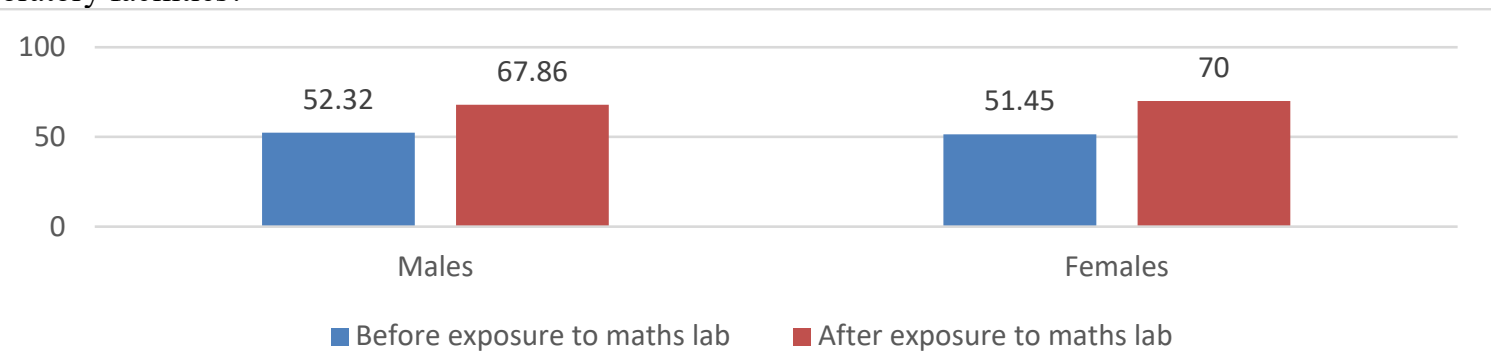

Fig 2. Gender achievement of students in number and numeration using mathematics laboratory facilities The outcome in Fig 2 showed that the male students' had mean scores of $52.32 \%$ and $67.86 \%$ before and after treatment respectively; while the females had $51.45 \%$ and $70 \%$ before and after treatment respectively. This means that the males were slightly higher before exposure to mathematics laboratory facilities but the females were slightly higher later.

\section{Test of Hypotheses}

H01. There is no significant effect of the use of math lab facilities on students' achievement in number and numeration.

Table 1.Effect of math lab facilities on students' achievement in number and numeration

\begin{tabular}{lrrrr}
\hline Source & Df & Mean Square & F & Sig. \\
\hline Corrected Model & 4 & 707.89 & 14.66 & 0.000 \\
Intercept & 1 & 639.58 & 13.25 & 0.001 \\
Pretest & 1 & 1.002 & 00.02 & 0.890 \\
Groups & 1 & 2736.05 & 56.66 & 0.000 \\
Error & 54 & 48.29 & & \\
Total & 59 & & & \\
Corrected Total & 58 & & & \\
\hline
\end{tabular}

It can be seen in Table 1 that the students did not differ significantly before the treatment $[\mathrm{F}(1,54)=0.02$, $\mathrm{p}>0.05]$, but they differ significantly after exposure to mathematics laboratory facilities $[F(1,54)=56.66 ; p<0.05]$. This led to the rejection of the first null hypothesis which states that exposing students to the use of mathematics laboratory facilities does not have any significant effect on their achievement in number and numeration. The findings corroborate with the result obtained in Fig 1. The implication is that the teachers' use of mathematics laboratory facilities was responsible for higher achievement score obtained by the students in number and numeration. But besides the usability of mathematics laboratory facilities, could other factors like gender contribute to the difference in pre and post achievement scores? This would be explicated in the next frame.

H02.There is no significant effect of gender on achievement of students in number and numeration when 
mathematics lab facilities are used for teaching.

Table 2.Effect of gender on achievement of students in number and numeration

\begin{tabular}{lrrrr}
\hline Source & df & Mean Square & F & Sig. \\
\hline Corrected Model & 4 & 707.887 & 14.660 & .000 \\
Intercept & 1 & 639.584 & 13.246 & .001 \\
Pretest & 1 & 1.002 & .021 & .886 \\
Gender & 1 & 11.905 & .247 & .622 \\
Groups & 1 & 2736.047 & 56.664 & .000 \\
Error & 54 & 48.286 & & \\
Total & 59 & & & \\
Corrected Total & 58 & & & \\
\hline
\end{tabular}

The outcome in Table 2 depicts that students did not differ significantly based on gender $\mathrm{F}(1,54)=0.25$; $\mathrm{p}>0.05$. Hence, the null hypothesis of no significant effect of gender on achievement of students in number and numeration when mathematics laboratory facilities are used for teaching was not rejected. The result is in line with the mean achievement scores depicted in Fig 2. This means that gender has no significant effect on students' achievement in number and numeration when exposed to mathematics laboratory facilities.

H03.There is no significant interaction effect of gender and usability of mathematics laboratory facilities on achievement of students in number and numeration when taught when given access to mathematics laboratory facilities.

Table 3.Interaction effect of gender and treatment on achievement in number and numeration

\begin{tabular}{lrrrr}
\hline Source & df & Mean Square & F & Sig. \\
\hline Corrected Model & 4 & 707.887 & 14.660 & .000 \\
Intercept & 1 & 639.584 & 13.246 & .001 \\
Pretest & 1 & 1.002 & .021 & .886 \\
Groups & 1 & 2736.047 & 56.664 & .000 \\
Gender * Groups & 1 & 3.188 & .066 & .798 \\
Error & 54 & 48.286 & & \\
Total & 59 & & & \\
Corrected Total & 58 & & & \\
\hline
\end{tabular}

The result in Table 3 revealed no significant interaction effect of gender and treatment on students' achievement in number and numeration under exposure to the use of mathematics laboratory facilities $F(1$, $54)=0.07 ; p>0.05$. Therefore, the null hypothesis of no significant interaction effect of gender and usability of mathematics laboratory facilities on achievement of students in number and numeration when taught with mathematics laboratory facilities not rejected. This means that the use of mathematics laboratory facilities in the teaching of number and numeration would always produce positive results irrespective of whether students are male or female.

\section{Discussions on findings}

It is obvious that there was significant difference between the achievement of students exposed to mathematical laboratory instructional approach teaching and those exposed to conventional method in number and numeration. This means that there was significant effect of mathematics laboratory approach on mean achievement scores of students taught number and numeration. The result is in harmony with that of Manjunath (2018), who discovered that students taught with mathematical laboratory instructional approach performed significantly better than the control group in number and numeration. The superiority of the approach over the conventional teaching method has also been reported by Etukudo (2006), who carried out a study on the effect of laboratory and discussion method of teaching on students' achievement in mathematics at the secondary school level.

The study also found that there was no significant effect of gender on mean achievement scores of students taught number and numeration using mathematics laboratory approach. The implication of this result is that the treatment is not gender selective, but is good for both male and female students alike. The outcome also harmonized with the findings of Janet (2017), Okigbo and Osuafor (2018) that found that neither male nor female students performed significantly better than the other.

Moreover, it reported no significant interaction effects of mathematics laboratory method and gender on students mean achievement scores in number and numeration. It shows that mathematics laboratory approach is superior to the conventional method irrespective of gender in fostering achievement in number and numeration. In 
this case, there is no need for separation of instructional method for male and female since mathematics laboratory approach should be used successfully for the two groups.

\section{Conclusion}

In conclusion, this study has revealed that students exposed to laboratory teaching approach had significantly higher academic achievement than their counterparts exposed to the conventional way of teaching. Mathematics concepts are retained when teachers adopt laboratory approach, and that no disparity exists in the achievement of male and female students when taught number and numeration using laboratory approach. The result of this study also provided pragmatic evidence that mathematics laboratory instructional approach is an appropriate teaching approach capable of improving the present ill achievement than convectional teaching method.

\section{Recommendations}

The following recommendations are made based on the findings of this study:

1. Mathematics teachers should be encouraged to use laboratory instructional approach by providing all the necessary materials needed for its effective implementation;

2. Government should establish mathematics laboratory in all schools like other science subjects laboratories;

3. Seminar/workshops should be organized for mathematics teachers in secondary school on the use of mathematics laboratory;

4. The study also recommends that BECE preparation of students should be given more serious attention because of its predicted values on students' WASSCE achievement. Furthermore, the BECE should be graded in stain like WASSCE to facilitate the relationship comparison of students in the two examinations;

5. Mathematics laboratory instructional approach is not gender sensitive; therefore, both male and female students should be involved in mathematics laboratory instructional approach to enhance their achievement in Number and Numeration and other topics in mathematics.

\section{References}

Abdulhamid, M. G., Abubakar, M., \&Tela, A. B. (2017). Cluster schools model of teachers professional development: Role on pupils active participation in mathematics class in Gombe State. Abacus: The Journal of the Mathematical Association of Nigeria, 42(2), 143-148.

Abiami, P.O.\&Odok, J.K. (2016).Factors in Students Achievement in Different Branches of Secondary School Mathematics. Journal of Education and Technology I (1), 161-168.

Adeniran, S. T. (2016). Factors Responsible for poor performance of students. ABACUS. The Journal of the Mathematical Association of Nigeria, 18, 32-48

Adenegan, K. E. (2012). Setting Mathematics Laboratory in Schools. Journal of Education and Technology, 2(1), $5-10$.

Akanmu, I. A. (2017). Integration of geogebra software into teaching and learning of mathematics in Nigeria senior secondary schools. Abacus: The Journal of the Mathematical Association of Nigeria, 42(1), 1-11.

Etsu, S. M. (2017). Effects of Mathematics Laboratory Based Approach and Peer Tutoring on Achievement of Slow Learners Among Junior Secondary School Students in Niger State, Nigeria. Unpublished Ph.D. Thesis, Department of Science Education, ABU, Zaria.

Etukudo, U. E. (2006). The Effect of Computer Assisted Instruction on Gender and Performance of Junior Secondary School in Mathematics. ABACUS. Journal of the Mathematical Association of Nigeria 27 (1), 18

Farlex (2020). Encyclopedia: Farlex Inc.

Imoko, B. I., \& Isa, S. A. (2015). Impact of computer Genues on pupils achievement in mathematics in primary achievement in mathematics in primary school in LafiaLocal Government Area: A tool for technological development. Proceedings of September 2015 AnnualNational Conference of the mathematical Association of Nigeria 63-71.

Kurumah, M. S. (2007). Effects of Ethnomathematics Approach on Students' interest in Geometry and Mensuration. ABACUS, The Journal of the Mathematical Association of Nigeria, 32 (1), 103-112

Malik, N. A. (2017). Perceptions of teachers and pupils on use of BridgeIT mobile application for Teaching mathematics in Lagos state, Nigeria (Unpublished doctoral dissertation): University of Ilorin, Ilorin, Nigeria.

Manjunath,D.(2018).MathematicsLaboratory:An Alternative Method of Instruction.Educational Research 2(5).

National Open University of Nigeria (2012).Primary mathematics curriculum and methods.Course Guide for PED144, Lagos.

Nneji, S. O., \&Alio, B. C. (2017). Effect of use of computer animations strategy on secondary school students' achievement and retention in algebra in Enugu State. Abacus: The Journal of the Mathematical Association of Nigeria, 42(1), 12-21.

Ogunkunle, R.A. (2000).Teaching of Mathematics in Schools. The Laboratory Approach.The Nigeria Teacher 
Today, 8(1,2): 80-184.

Okigbo, E.C. \&Osuafor, A.M. (2018).Effects of Using Mathematics Laboratory in Teaching Mathematics on the Achievement of Mathematics Students.Educational Research Review, 3(8) 257-261.

Pasha, K., Rao, N. J., \& Veerababu, P. (2012). Importance of Mathematics Laboratory in High School Level. IOSR, Journal of Mathematics (IOSRJM) 1(4), 24-28.

Sambo, A.A. (2018). Research Method in Education. Ibadan:StrillingHorda.

Sheedevi, T. \& Asha, K. D. V. (2014). Effects of Mathematics laboratory based approach on achievement of Students of class VII in Mathematics. India Educational Review, 26(4), 15-34.

West African Examinations Council.(2010, 2011, 2012 \&2018).Chief Examiners' Report. Lagos: West African Examinations Council. 